\title{
Ectopia Cordis Associated with Pentalogy of Cantrell-A Case Report
}

\section{Ectopia cordis associada à pentalogia de Cantrell-relato de caso}

\author{
José Mauro Madi ${ }^{1}$ José Roberto Festugatto ${ }^{2}$ Matheus Rizzon ${ }^{2}$ Ana Paula Agostini ${ }^{3}$ \\ Breno Fauth de Araújo ${ }^{3}$ Rosa Maria Rahmi Garcia 4
}

${ }^{1}$ Department of Obstetrics and Gynecology, Faculty of Medicine,

Address for correspondence José Mauro Madi, MD, PhD,

Universidade de Caxias do Sul, Caxias do Sul, RS, Brazil

Departamento de Obstetrícia e Ginecologia, Faculdade de Medicina,

2 Department of Radiology, Hospital Geral de Caxias do Sul,

Universidade de Caxias do Sul, Caxias do Sul, RS, Brazil

${ }^{3}$ Department of Pediatrics and Neonatology, Faculty of Medicine, Universidade de Caxias do Sul, Avenida Prof. Antônio Vignolli, 255, Campus Universitário, 95001-970, Caxias do Sul, RS, Brazil

Universidade de Caxias do Sul, Caxias do Sul, RS, Brazil (e-mail: jmauromadi@gmail.com).

${ }^{4}$ Department of Endocrinology, Faculty of Medicine, Universidade de Caxias do Sul, Caxias do Sul, RS, Brazil

Rev Bras Ginecol Obstet 2019;41:352-356.

\begin{abstract}
Pentalogy of Cantrell (PC) is a rare congenital anomaly characterized by changes in the

Keywords

- ectopia cordis

- pentalogy of Cantrell

- abdominal wall defects

- congenital heart defects

- umbilical hernia

\section{Resumo}

Palavras-chave

- ectopia cordis

- pentalogia de Cantrell

- defeitos da parede abdominal

- defeitos congênitos cardíacos

- hérnia umbilical mesodermal median structures and congenital heart disease, often with a poor prognosis. In 1958, Cantrell et $\mathrm{al}^{2}$ defined the full spectrum of the syndrome with the following anomalies: defects of the anterior diaphragm, of the lower part of the sternum, of the supraumbilical region and the abdominal wall, of the diaphragmatic pericardium, and various intracardiac congenital abnormalities. The present report describes a case of ectopia cordis associated with PC and the importance of the participation of a multidisciplinary team in the treatment of this condition.

A pentalogia de Cantrell (PC) é uma rara anomalia congênita caracterizada por alterações nas estruturas medianas mesodérmicas e doenças cardíacas congênitas, cursando muitas vezes com um mau prognóstico. Em 1958, Cantrell et al ${ }^{2}$ definiram o espectro completo da síndrome com as seguintes anomalias: defeitos do diafragma anterior, da parte inferior do esterno, da região supraumbilical e parede abdominal, do pericárdio diafragmático, e várias anormalidades congênitas intracardíacas. O presente relato relaciona-se a um caso de ectopia cordis associado à $P C$ e à importância da participação de uma equipe multidisciplinar no acompanhamento da doença.
\end{abstract}

\section{Introduction}

Pentalogy of Cantrell (PC) is a rare congenital syndrome, often with a poor prognosis, whose prevalence may range from 1 to

(DD José Mauro Madi's ORCID is https://orcid.org/0000-0002-2345-4713.

received

August 10, 2018

accepted

January 17, 2019
65 per 200,000 births. ${ }^{1}$ In 1958 , Cantrell et al, ${ }^{2}$ from the Johns Hopkins University, reported the syndrome for the first time. These authors defined the full spectrum of the syndrome with the following anomalies: defects of the anterior diaphragm, of the lower part of the sternum, of the supraumbilical region and in the abdominal wall, of the diaphragmatic pericardium, and
Copyright $\odot 2019$ by Thieme Revinter Publicações Ltda, Rio de Janeiro, Brazil

License terms

$10.1055 / \mathrm{s}-0039-1679878$ ISSN $0100-7203$. 


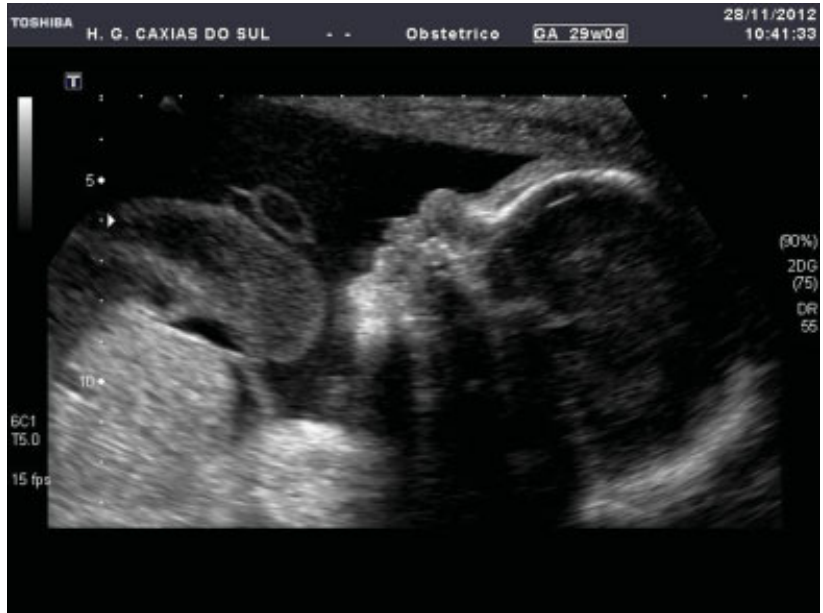

Fig. 1 Large intraabdominal cyst on the fetal abdomen on sonographic examination.

various intracardiac congenital abnormalities. The literature regarding this topic has presented few patients with the full spectrum of the pentalogy. ${ }^{1-6}$ We report the case of a newborn who, in the $2^{\text {nd }}$ trimester of pregnancy, with the aid of $2 \mathrm{D}$ combined with 3D ultrasound (US) ( - Fig. 1), fetal echocardiography and magnetic resonance imaging (MRI) (-Figs. 2 and 3), had a confirmed diagnosis of a large omphalocele, as well as of evisceration of part of the fetal liver, of the intestine, of the apex of the heart, and a defect in the interventricular septum and in the interatrial septum, along with a diaphragmatic hernia and a poor closing of the sternum. Surgical correction of the omphalocele was attempted with myocutaneous flaps. However, as a result of a progressive respiratory dysfunction, neonatal death occurred on the $32^{\text {nd }}$ day of life. The authorization of the family to perform an autopsy examination was not obtained. The present research was conducted

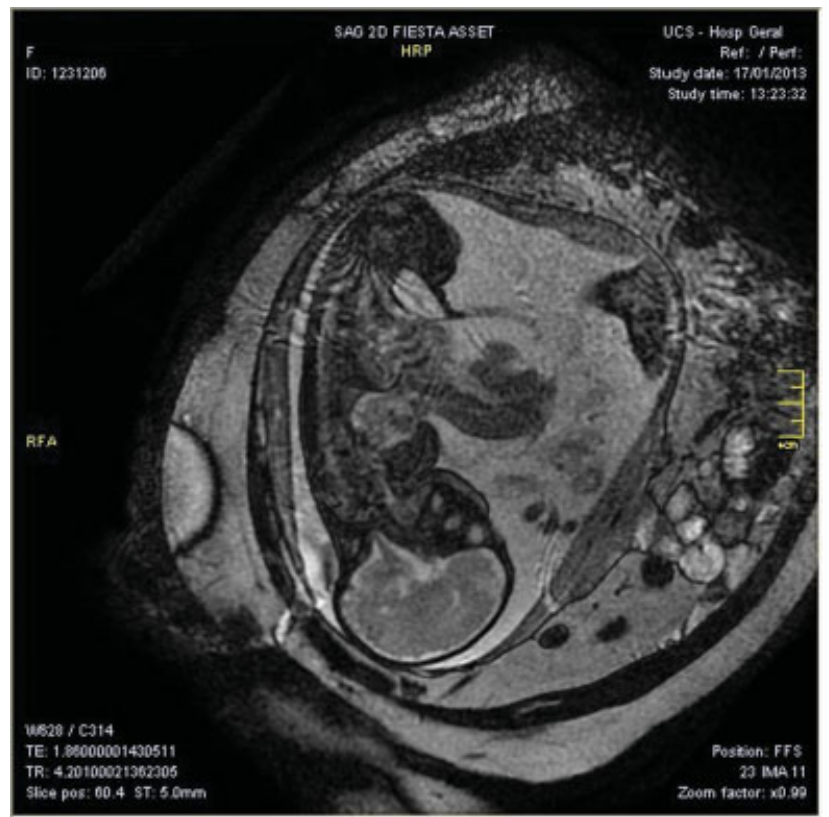

Fig. 2 Longitudinal section. MRI shows the opening of the abdomen and exteriorization of the cyst.

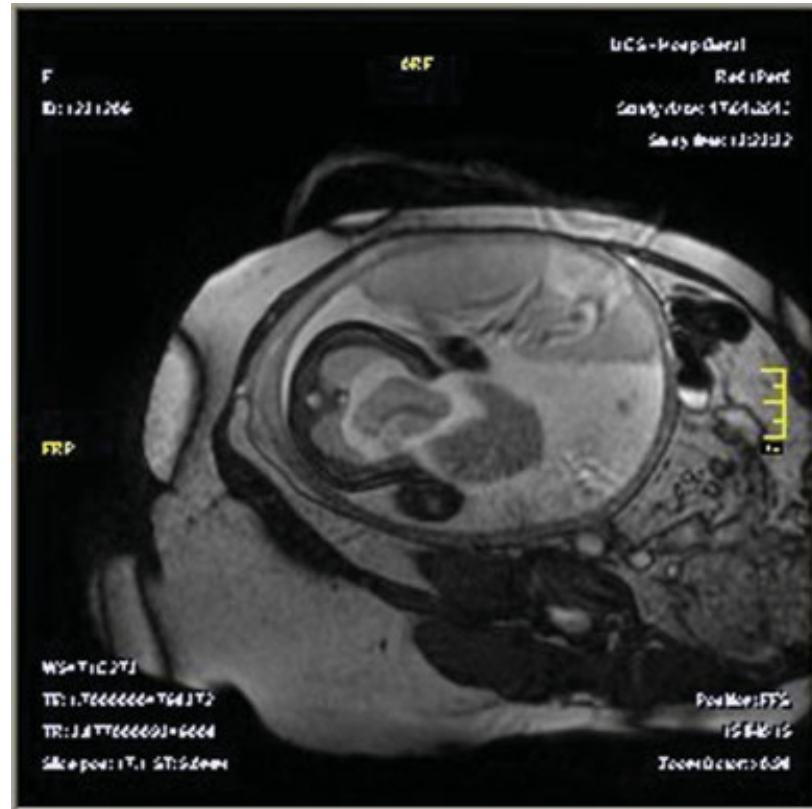

Fig. 3 Cross-section. MRI shows the opening of the abdomen and exteriorization of the cyst.

in accordance with the ethical standards of all applicable national and institutional committees, as well as with the Helsinki Declaration of the World Medical Association.

\section{Case Description}

A 29-year-old woman of African descent in her third pregnancy, 0 positive blood, smoker (ten cigarettes/day), was referred to the High-Risk Pregnancy Care Clinic at the Hospital Geral of the Universidade de Caxias do Sul, Caxias do Sul, state of Rio Grande do Sul, Brazil, as a result of her 2D US revealing a fetus with defects in the abdominal wall. On admission, two births by cesarean section were reported, while the second child had presented a malformation of the esophagus at birth. The prenatal exams for the $1^{\text {st }}, 2^{\text {nd }}$, and $3^{\text {rd }}$ trimesters were normal. Twelve consultations for the monitoring of the unplanned pregnancy were conducted. Both the woman and her family were aware of the fetal malformation and demonstrated the desire to maintain the pregnancy. Because of the identification of the omphalocele in the US, the woman underwent a fetal echocardiography that confirmed the diagnosis of a complete atrioventricular septal defect, of a perimembranous interventricular septal defect of the entry pathway, and of a probable interatrial septal defect of the ostium primum type.

The US findings can be summarized as follows: in the $16^{\text {th }}$ week of pregnancy, no changes were detected in the fetal anatomy; in the $26^{\text {th }}$ week, an echogenic mass was observed in the abdominal wall, as well as a fetal omphalocele of $5 \mathrm{~cm}$; in the $29^{\text {th }}$ week, a closing defect was found in the thoracicoabdominal wall, extruding from part of the liver and from the apex of the heart, wrapped by a thin membrane, associated with a pericardial effusion, suggesting PC. In all of the tests, the amniotic volume was normal. 


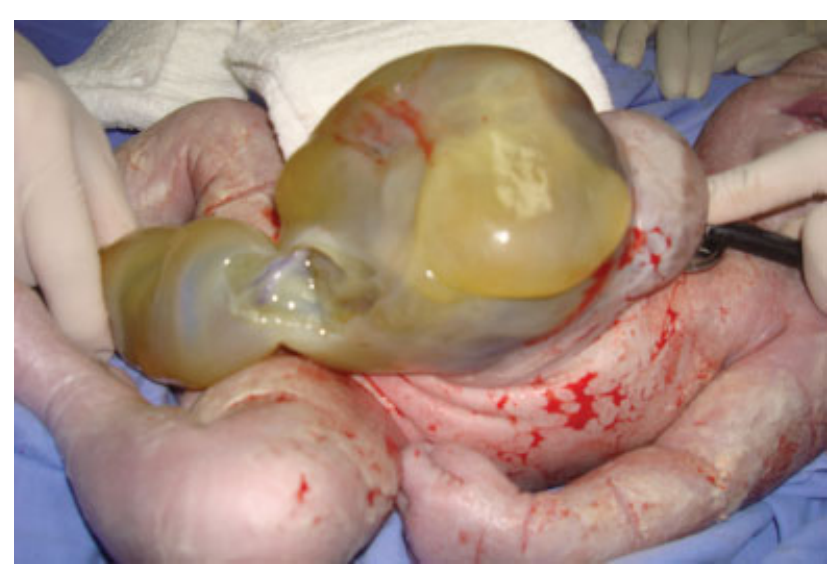

Fig. 4 Large cyst in newborn abdomen and part of umbilical cord. To the right of the picture, over the stethoscope, part of the fetal liver and heart.

A female baby was born at the $38^{\text {th }}$ gestational week by elective cesarean delivery. The newborn measured $46 \mathrm{~cm}$ and weighed $3,600 \mathrm{~g}$, with head circumference of $35 \mathrm{~cm}$ and thoracic perimeter of $32 \mathrm{~cm}$. The newborn had an Apgar score of 3 and 7 in the $1^{\text {st }}$ and $5^{\text {th }}$ minutes, respectively. In the ectoscopy, the conceptus presented a voluminous omphalocele with evisceration of the heart, of the liver, and of the intestinal loops, diaphragmatic hernia, heart located in the abdomen, congenital defect of the distal third of the sternum, and heart abnormalities (-Fig. 4). The treatment of the omphalocele with myocutaneous flaps was considered, in order to achieve a closure of the PC. Due to the early and progressive respiratory impairment, conventional mechanical ventilation was installed. On the $10^{\text {th }}$ day of life, closure of the abdomen with an amniotic membrane was attempted, with the aid of a silicone and Marlex mesh (Atramat ${ }^{\circledR}$ Internacional Farmaceutica, S.A. de C.V., Lerma, Edo. de México, México). In spite of the proposed treatment, the newborn remained dyspneic, progressed poorly and died on the $32^{\text {nd }}$ day of life resulting from sepsis, respiratory failure, edema of the head and upper thorax, and thrombosis of the inferior vena cava and of the right femoral vein.

\section{Discussion}

In 1958 , Cantrell et $\mathrm{al}^{2}$ reported 5 cases of children with ectopia cordis (EC), associated with congenital defects affecting the diaphragm (diaphragmatic hernia), the abdominal wall (omphalocele), pericardium (partially missing), heart (ventricular septal defect), and part of the sternum (partial opening with defective closure of the midline). The authors suggested that the unknown etiology originated from a defect in the embryonic development around the $14^{\text {th }}$ and $18^{\text {th }}$ day of gestation. Consequently, the development would not occur in the transverse septum of the diaphragm, nor would it occur in the migration of the upper abdominal mesodermal folds in the ventromedial direction. In this situation, some organs could be extruded through the defect that would originate in the abdominal wall and in the sternum. ${ }^{6}$ It is cited that EC can present itself in the form of a total or partial displacement of the heart, or what has been described as cervical, cervicothoracic, and thoracoabdominal displacements. ${ }^{7}$ The left ventricular diverticulum is present in between 20 and $50 \%$ of the cases. Other heart defects that can be seen are the tetralogy of Fallot (17 to 20\%), and ventricular septal defect (VSD) (100\%), atrial septal defect (ASD) (53\%), interatrial communication (34.6\%), pulmonary stenosis or atresia (31.5\%), transposition of the major arteries, tricuspid atresia, truncus arteriosus, and atrioventricular septal defect. A double outlet of the right ventricle is found in $1.2 \%$ of the cases. ${ }^{4,8-11}$ Other anomalies may be observed in patients with PC, namely: craniofacial and central nervous system defects, such as cleft lip and/or palate, encephalocele, hydrocephalus, craniorachischi$\operatorname{sis}^{4,7,12-14}$, as well as defects of the abdominal organs, such as agenesis of the gallbladder and polysplenia. ${ }^{15}$

Due to various phenotypes related to the defect of the abdominal wall in the PC, multiple factors are said to be responsible, including teratogenic mechanics, major genetic mutations, and chromosome abnormalities, such as trisomy 13 and $18 .^{16}$ The mutation of the thoracoabdominal syndrome (TAS) gene, mapped in the area Xq25-q26.1, is mentioned as having involvement in the fusion of the sternum, as well as in multiple heart defects and diaphragmatic and abdominal wall defects, along with other changes mentioned in some cases of PC. 6,17

In some cases, the spectrum of the PC had not been present in a complete manner, and so, in 1972 , Toyama ${ }^{18}$ suggested the following classification of PC: Class 1-definitive diagnosis, with the presence of all 5 defects present; Class 2-probable diagnosis, with the presence of 4 defects, including abnormalities of the intracardiac and of the ventral walls; Class 3-incomplete, with the presence of various combinations of defects, including a sternal abnormality. In the present case, the sternum was found open, associated with the bulky omphalocele and with the diaphragmatic and intracardiac defects. ${ }^{18}$

The performance of a sonogram exam during the first prenatal period allows for the diagnosis of PC in the first gestational trimester, ${ }^{19}$ which is characterized by a pericardial effusion associated with an anterior diaphragmatic hernia and pericardial diaphragmatic defects. ${ }^{20}$ The association with magnetic resonance imaging (MRI) exams will confirm the fetal anomalies. ${ }^{21}$ The fetal echocardiography has become essential in the confirmation of the diagnosis of the cardiac abnormalities associated with the PC. Conventional US or radiography can identify other features of the PC and of associated anomalies. However, small defects in the diaphragm and in the pericardium can be extremely difficult to be diagnosed accurately. In these cases, or even in cases of possible surgery, MRI can be useful. ${ }^{22,23}$

In the present case, the association of $2 \mathrm{D}$ and $3 \mathrm{D}$ US has become a valuable tool in the diagnosis, allowing for the most suitable way of counseling a pregnant woman and her family. The use of 3D US can be very useful in the diagnosis of fetal anomalies. However, the diagnosis of PC, in general, can be proposed through the traditional 2D images. In general, the 2D US is sufficient to make the diagnosis in the $1^{\text {st }}$ trimester, 
while the 3D US has greater usefulness for the diagnosis in the $2^{\text {nd }}$ and $3^{\text {rd }}$ trimesters. ${ }^{24,25}$ It has been suggested that MRI exams provide a better assessment of fetuses with this syndrome. ${ }^{21,26}$ However, in cases of major defects similar to those being presented, we believe that a combination of $2 \mathrm{D}$ and 3D US is sufficient.

A major malformation would be clearly identified by the US, and considering the poor prognosis that comes with major defects, we believe that MRI exams would not add any additional information to aid in the counseling of the patient. However, for pregnant women whose fetuses present minor or transient defects, and for those who have decided to maintain the pregnancy, echocardiography, MRI and fetal echocardiography can help in determining the prognosis, detailing information for the pediatric and surgical teams that will provide care to the newborn after the delivery. ${ }^{27}$ In the present case, we found that the 2D and 3D US, the MRI and the fetal echocardiography constituted important tools in the diagnosis and in the subsequent evaluations of the prenatal care. We also believe that the MRI and echocardiography exams were able to provide a more specific diagnosis, which provided the obstetric and neonatal units with a more specific approach.

The treatment of the PC consists of cardiovascular surgery, as well as the palliative surgical corrections of the ventral hernia, of the diaphragmatic defects, and of the associated anomalies. Action strategies will be based on the size of the defect in the abdominal wall, on the abnormalities in the heart, and on the type of EC.

To identify prognostic factors that could help in identifying the best proposal for the treatment of patients with PC, van Hoorn et al, in 2008, ${ }^{26}$ performed an excellent literature review, which identified 58 patients with PC, between 1987 and April 2007, of which 33 were described as having complete PC, and 23 as having incomplete PC. Two of the patients were not clearly defined as complete or incomplete. Fourteen patients had EC without cardiac malformations, 16 patients had intracardiac defects without EC, and 23 had both. Other associated abnormalities were described in 29 of the patients. Out of the 58 patients cited, including patients in whom the pregnancy was interrupted, 37 died a few days after birth. In this group, the mortality was highest in patients with associated abnormalities and in the presence of the complete form. The surviving patients with EC were those who were associated with intracardiac abnormalities. This suggests that the intracardiac defects may indicate a more favorable prognosis, although it could be considered a bias of interpretation due to the small number of patients. ${ }^{26}$

With the exception of omphalocele, which should be corrected as soon as possible, the main surgical indications are related to heart defects, with the objective of repairing the abdominal, thoracic and cardiac defects. The truncation of the left ventricular diverticulum can be performed with or without extracorporeal circulation, provided that the mitral valve can be preserved. ${ }^{28,29}$ A ventricular diverticulum resection is indicated shortly after birth due to the risk of spontaneous or traumatic rupture and sudden death due to tachyarrhythmia (which occurs in between 6 and 20\% of the cases). ${ }^{30}$ Severe abnormalities associated with a relatively stable heart defect can motivate the correction of the defects, as soon as possible. The lower abdominal wall defects can be repaired after the correction of the intracardiac defects. ${ }^{15,16}$

The caregiver team should be composed of an obstetrician, a neonatologist, a pediatric cardiologist, a geneticist, and a pediatric surgeon, who must use their experience in choosing the best approach to be offered for the treatment of this severe complication. ${ }^{31}$

\section{Conclusion}

In conclusion, the prognosis appears to be more pessimistic in patients with the complete form of PC, EC and associated anomalies. Intracardiac changes do not seem to be a negative prognostic factor. When the PC diagnosis is suspected, the multidisciplinary approach becomes essential.

Conflicts of Interest

The authors have no conflicts of interest to declare.

\section{References}

1 Desselle C, Herve P, Toutain A, Lardy H, Sembely C, Perrotin F. Pentalogy of Cantrell: sonographic assessment. J Clin Ultrasound 2007;35(04):216-220. Doi: 10.1002/jcu.20318

2 Cantrell JR, Haller JA, Ravitch MM. A syndrome of congenital defects involving the abdominal wall, sternum, diaphragm, pericardium, and heart. Surg Gynecol Obstet 1958;107(05):602-614

3 Rodgers EB, Monteagudo A, Santos R, Greco A, Timor-Tritsch IE. Diagnosis of pentalogy of Cantrell using 2- and 3-dimensional sonography. J Ultrasound Med 2010;29(12):1825-1828. Doi: 10.7863/jum.2010.29.12.1825

4 Correa-Rivas MS, Matos-Llovet I, García-Fragoso L. Pentalogy of Cantrell: a case report with pathologic findings. Pediatr Dev Pathol 2004;7(06):649-652

5 Onderoğlu L, Baykal C, Tulunay G, Talim B, Kale G. Prenatal diagnosis of Cantrell's pentalogy: a case report. Turk J Pediatr 2003;45(04): 357-358

6 Carmi R, Boughman JA. Pentalogy of Cantrell and associated midline anomalies: a possible ventral midline developmental field. Am J Med Genet 1992;42(01):90-95. Doi: 10.1002/ajmg.1320420118

7 Morales JM, Patel SG, Duff JA, Villareal RL, Simpson JW. Ectopia cordis and other midline defects. Ann Thorac Surg 2000;70(01): 111-114. Doi: 10.1016/S0003-4975(00)01388-6

8 Iyer AP, Vijayakumar A, Bansal N, Rema KS. Cantrell's syndrome: a report of two cases. Indian J Thoracic Cardiovascular Surg. 2005; 21:283-284. Doi: 10.1007/s12055-005-0009-3

9 Marijon E, Hausse-Mocumbi AO, Ferreira B. Cantrell's syndrome. Cardiol Young 2006;16(01):95-96. Doi: 10.1017/S1047951105 002192

10 Halbertsma FJ, van Oort A, van der Staak F. Cardiac diverticulum and omphalocele: Cantrell's pentalogy or syndrome. Cardiol Young 2002;12(01):71-74. Doi: 10.1017/S1047951102000148

11 Grethel EJ, Hornberger LK, Farmer DL. Prenatal and postnatal management of a patient with pentalogy of Cantrell and left ventricular aneurysm. A case report and literature review. Fetal Diagn Ther 2007;22(04):269-273. Doi: 10.1159/000100788

12 Polat I, Gül A, Aslan H, et al. Prenatal diagnosis of pentalogy of Cantrell in three cases, two with craniorachischisis. J Clin Ultrasound 2005;33(06):308-311. Doi: 10.1002/jcu.20134

13 Pivnick EK, Kaufman RA, Velagaleti GV, Gunther WM, Abramovici D. Infant with midline thoracoabdominal schisis and limb defects. Teratology 1998;58(05):205-208. Doi: 10.1002/(SICI)1096-9926 (199811)58:5<205:AID-TERA7>3.0.CO;2-X 
14 Uygur D, Kiş S, Sener E, Günçe S, Semerci N. An infant with pentalogy of Cantrell and limb defects diagnosed prenatally. Clin Dysmorphol 2004;13(01):57-58

15 Bittmann S, Ulus H, Springer A. Combined pentalogy of Cantrell with tetralogy of Fallot, gallbladder agenesis, and polysplenia: a case report. J Pediatr Surg 2004;39(01):107-109. Doi: 10.1016/j. jpedsurg.2003.09.030

16 Chen CP. Syndromes and disorders associated with omphalocele (II): OEIS complex and Pentalogy of Cantrell. Taiwan J Obstet Gynecol 2007;46(02):103-110. Doi: 10.1016/S1028-4559(07)60003-5

17 Martin RA, Cunniff C, Erickson L, Jones KL. Pentalogy of Cantrell and ectopia cordis, a familial developmental field complex. Am J Med Genet 1992;42(06):839-841. Doi: 10.1002/ajmg.1320420619

18 Toyama WM. Combined congenital defects of the anterior abdominal wall, sternum, diaphragm, pericardium, and heart: a case report and review of the syndrome. Pediatrics 1972;50(05):778-792

19 Liang RI, Huang SE, Chang FM. Prenatal diagnosis of ectopia cordis at 10 weeks of gestation using two-dimensional and threedimensional ultrasonography. Ultrasound Obstet Gynecol 1997; 10(02):137-139. Doi: 10.1046/j.1469-0705.1997.10020137.x

20 Siles C, Boyd PA, Manning N, Tsang T, Chamberlain P. Omphalocele and pericardial effusion: possible sonographic markers for the pentalogy of Cantrell or its variants. Obstet Gynecol 1996;87(5 Pt 2):840-842

21 McMahon CJ, Taylor MD, Cassady CI, Olutoye OO, Bezold LI. Diagnosis of pentalogy of cantrell in the fetus using magnetic resonance imaging and ultrasound. Pediatr Cardiol 2007;28(03): 172-175. Doi: 10.1007/s00246-006-0032-1

22 Oka T, Shiraishi I, Iwasaki N, Itoi T, Hamaoka K. Usefulness of helical CT angiography and MRI in the diagnosis and treatment of pentalogy of Cantrell. J Pediatr 2003;142(01):84. Doi: 10.1067/ mpd.2003.mpd031
23 Song A, McLeary MS. MR imaging of pentalogy of Cantrell variant with an intact diaphragm and pericardium. Pediatr Radiol 2000; 30(09):638-639. Doi: 10.1007/s002470000288

24 Peixoto-Filho FM, do Cima LC, Nakamura-Pereira M. Prenatal diagnosis of Pentalogy of Cantrell in the first trimester: is 3dimensional sonography needed? J Clin Ultrasound 2009;37(02): 112-114. Doi: $10.1002 /$ jcu.20498

25 Araujo Júnior E, Zanforlin Filho SM, Guimarães Filho HA, Pires CR, Nardozza LM, Moron AF. Diagnosis of Pentalogy of Cantrell by three-dimensional ultrasound in third trimester of pregnancy. A case report. Fetal Diagn Ther 2006;21(06):544-547. Doi: 10.1159/ 000095670

26 van Hoorn JHL, Moonen RMJ, Huysentruyt CJR, van Heurn LWE, Offermans JPM, Mulder ALM. Pentalogy of Cantrell: two patients and a review to determine prognostic factors for optimal approach. Eur J Pediatr 2008;167(01):29-35. Doi: 10.1007/s00431-007-0578-9

27 Aslan A, Karagüzel G, Unal I, Aksoy N, Melikoglu M. Two rare cases of the Pentalogy of Cantrell or its variants. Acta Med Austriaca 2004;31(03):85-87

28 Bhat RY, Rao A, Muthuram. . Cantrell syndrome in one of a set of monozygotic twins. Singapore Med J 2006;47(12):1087-1088

29 Chandran S, Ari D. Pentalogy of cantrell: an extremely rare congenital anomaly. J Clin Neonatol 2013;2(02):95-97. Doi: 10.4103/2249-4847.116410

30 Bick D, Markowitz RI, Horwich A. Trisomy 18 associated with ectopia cordis and occipital meningocele. Am J Med Genet 1988; 30(03):805-810. Doi: 10.1002/ajmg.1320300313

31 Mallula KK, Sosnowski C, Awad S. Spectrum of Cantrell's pentalogy: case series from a single tertiary care center and review of the literature. Pediatr Cardiol 2013;34(07):1703-1710. Doi: 10.1007/s00246-013-0706-4 